\title{
La representación del rol femenino en la música de traficantes de drogas
}

Anajilda Mondaca Cota ${ }^{1}$

\section{Introducción}

$\mathbf{P}$

or mucho tiempo, los estudios sobre el contenido de discursos de toda índole han sido preocupación de los antiguos filósofos, estudiosos de la retórica, el arte, etc., quienes buscaban la interpretación de los símbolos y del lenguaje, ya fuera con fines políticos o sociales. En la actualidad los fenómenos simbólicos son del interés de la literatura, la educación, la crítica de los medios masivos, así como de la psicología, la sociología, la lingüística, entre otras, y en actividades profesionales como la publicidad y la política, por mencionar algunas.

La temática planteada en este trabajo, en primer lugar obedece a un interés profesional y personal por conocer todas las connotaciones posibles dentro de los corridos de traficantes de drogas, en especial las relacionadas con la mujer, pues si bien la mayor parte de los corridos narran historias de hombres, en gran parte de ellos la incluyen, ya sea como sujeto de compañía o relación amorosa. En cambio, en los discursos analizados su papel es diferente, encontramos una mujer más activa, audaz, valiente, decidida y dispuesta a enfrentamientos de todo tipo. En segundo lugar, forma parte de una investigación en proceso para la obtención del grado de maestría en Comunicación para el Desarrollo Social y del proyecto de investigación "Las expresiones culturales de Sinaloa: el caso del corrido de traficantes de drogas", en coordinación con la Universidad Autonoma de Sinaloa y la Academia de Ciencias Penales de Sinaloa.

Sin pretender realizar un estudio de género a profundidad, se consideró importante abordar el tema por la sencilla razón de que estamos hablando de

1. Universidad de Occidente, campus Culiacán. Correo electrónico: anajilda@hotmail.com. 
mujeres y su relación con los hombres, y como actores su presencia en las historias es vital, además de ser los sujetos de la construcción social de género. Sólo para hacer más concreto este trabajo, lo hemos dedicado al rol femenino, además de no encontrar, a la fecha, registros de estudios sobre mujeres representadas simbólicamente en discursos musicales de esta naturaleza, como es el de los narcotraficantes. En razón de lo anterior, incluimos algunos conceptos, categorías y aspectos teóricos, los cuales se fueron incorporando como elementos de interpretación en las unidades analizadas. Asimismo, la información incluida acerca del narcotráfico permitió encontrar significados muy interesantes, en especial de signos lingüísticos y de términos nuevos, los cuales son utilizados en ese ambiente y son los que definen finalmente la intención de los mensajes en los narcocorridos.

\section{De la metodología}

Con las primeras categorías identificadas en una lectura rápida de los corridos analizados, surgen también las primeras interrogantes: ¿Cuál es la función de la mujer en estas historias?, ¿qué papel desempeña?, ¿qué trabajos realiza?, iexiste alguna diferencia entre el rol tradicional y esta nueva mujer narcotraficante? Por supuesto, inferir las respuestas requiere de un amplio conocimiento no sólo de análisis, también del contexto y de los datos referenciales. A través de la metodología de análisis de contenido propuesta por Klaus Krippendorff se pretende explorar e identificar desde la lingüística y la literatura aquellas representaciones simbólicas en el lenguaje de los corridistas (compositores de corridos), donde lo contado y cantado es tan real como la propia existencia de muchos de los personajes ahí descritos. De acuerdo con el diseño de los componentes del modelo de este autor, tenemos en el objeto de análisis y/o datos a los corridos de traficantes de drogas.

De los más de 250 narcocorridos localizados, $10 \%$ aproximadamente (25 narcocorridos) incluyen a mujeres como protagonistas; en un porcentaje similar aparecen como objeto de compañía y ostentación, pareja o cómplice. Los versos y las estrofas corresponden a las unidades de registro con los signos correspondientes por analizar, ya sean palabras o versos, o bien estrofas completas.

En cuanto a la clasificación de las unidades temáticas, hemos tomado algunos aportes del método de R. M. Volkov (en Propp, 1986), quien en sus análisis del cuento ruso hace una clasificación por asuntos o temas como posibilidad de estudio. Con lo que este autor denomina la Ley de permutabilidad se procuró agrupar los títulos de los corridos dentro de uno o varios asuntos, en virtud de que según esta ley, fragmentos enteros de un cuento 
pueden ser transferidos a otro sin sufrir modificaciones, y a la vez adaptarse de acuerdo a la historia; también pueden ser variables, basta distinguir el o los asuntos, adaptarlos y relacionarlos con otras historias. Así, para realizar una clasificación de los corridos de traficantes de drogas se tomó en cuenta: el título, el cual nos puede inducir al tema; el tema o los temas en sí; y el contenido del discurso, encontrando que uno o varios temas aparecen en uno o varios corridos.

En cuanto a metodología, desde la perspectiva de género aún no se ha encontrado un modelo de análisis que nos permita analizar los roles de los actores, los hombres y las mujeres protagonistas de los narcocorridos. Sin embargo, categorías como la sexualidad, el sexismo, la desigualdad, el poder, el cuerpo, entre otras, fueron de importante aplicación a las interpretaciones de los signos lingüísticos, según se fueron identificando los roles femeninos. Estas categorías se describen más adelante.

\section{De la construcción de género}

A partir de la asignación de roles tradicionales, la mujer había permanecido "invisible", al margen de la aceptación social; sus roles no eran significativos ni representaban interés alguno por ser estudiados. Ramos (1991) señala que los estudios acerca de "la mujer como objeto de análisis", llamaron la atención a feministas y antropólogos desde hace más de 40 años y en la medida que fueron desarrollándose nuevas generaciones de feministas empezaron a hacer cuestionamientos sobre la identidad femenina, los elementos que la constituyen, el significado de feminidad, lo cual los llevó a buscar respuestas en las diversas disciplinas de las ciencias sociales y las humanidades; es entonces cuando aparece una nueva categoría, a la que le dan el concepto de género, entendido éste como "el conjunto de relaciones sociales que, con base en las características biológicas regula, establece y reproduce las diferencias entre hombres y mujeres" (Ramos, 1991: 12). Sin embargo, cuando se hace referencia al género como construcción social, es frecuente vincular el concepto únicamente con las mujeres sin incluir al hombre, y no pensamos que desde el punto de vista conceptual-social ambos sujetos deben ser tomados en cuenta, pues los roles culturales que le corresponden jugar al hombre, en su mayoría, tienen una asociación directa con el rol femenino. De acuerdo con Rodríguez y Corrales (1999) es indispensable estudiar acerca de las mujeres, pero también de los hombres, ya que no es posible entenderlas separadas de la sociedad, al contrario, deben estudiarse como parte integral de ésta, sólo así la perspectiva de género se conforma en un ámbito con nuevos elementos de análisis y con la posibilidad de ver y entender al mundo de una manera 
diferente. Por su parte, Conde (2000) señala que las feministas buscan un cambio de la cultura y el funcionamiento de las instituciones, de tal forma que no haya ninguna diferencia entre lo masculino y lo femenino, es decir, hacer una deconstrucción del sentido y del significado del término. Esta misma autora anota diversos conceptos sobre género aportados por feministas e instituciones, donde predomina la idea de que la mujer no es diferente del varón (Feministas del género); éstos son seres biológicos que al socializar se definen como masculinos o femeninos (Naila Kabeer); es un sistema de roles y relaciones entre el hombre y la mujèr determinados no biológicamente, sino por el contexto social, político y económico (ONU); se diferencia de la palabra sexo para expresar la realidad de que la situación y los papeles de la mujer y del hombre son construcciones sociales sujetas a cambio (Congreso de Estados Unidos, Bella Abzug).

En lo que respecta al tema de género y comunicación, según Pearson (1993), es de gran importancia debido a los grandes cambios psicológicos y sociológicos experimentados actualmente, en especial porque los medios de comunicación se han encargado de explicar y difundir los cambios existentes de los roles asumidos por los hombres y las mujeres y a la vez comunican y trasmiten nuevos roles, donde la elección para cambiar de roles forma parte de lo que culturalmente vivimos. La autora agrega que los individuos modifican su comportamiento de acuerdo con sus necesidades y las satisfacciones que el entorno les proporcione. De acuerdo con estas ideas, el presente trabajo tiene relación precisamente con los cambios del rol femenino y sus representaciones simbólicas en los contenidos de los corridos de traficantes de estupefacientes, tomando en cuenta el contexto social y cultural en el que se desarrolla el narcotráfico, y las implicaciones sociales y culturales que ello ha generado en el entorno no sólo regional y nacional, su influencia es a nivel mundial (sobre todo con la publicación de la novela La Reina del Sur, de Pérez Reverte, de cuya historia existen dos versiones de narcocorrido), y los medios han tenido su parte, pues se reconoce la enorme difusión que han dado a este género musical y su poderosa penetración.

\section{De las categorías de género}

Las siguientes son algunas de las categorías encontradas en diversos autores y de las cuales algunas de ellas están aplicadas al análisis.

Sexo. En una primera acepción, Saltzman (1989) establece la existencia de diferencias biológicas, mínimo-cromosómicas, hormonales y morfológicas entre hombres y mujeres. Un segundo significado se refiere a la definición 
sociocultural del sexo biológico; es decir, la construcción social desde la perspectiva de género.

Sexualidad. Constituye un elemento importante de las relaciones amorosas e íntimas. La conducta sexual femenina mantiene relación con el hecho de estar enamorado y de tener una relación estable, mientras la sexualidad masculina se relaciona más indirecta y menos exclusivamente con el romanticismo y la intimidad de la relación (Pearson, 1993).

Sexismo. Denota un tipo de discriminación particular. Es una forma injusta e inapropiada de tratar a los demás. Es la forma en que un hombre o una mujer son discriminados "porque se cree que su sexo biológico les asegura, les autoriza y les predispone" a poseer y a ejercer un número determinado de ventajas sobre los demás (Pearson, 1993: 28). Las mujeres son menos sexistas que los hombres, por lo que se espera de ellas menos discriminación o trato injusto hacia los otros o hacia sus iguales.

El cuerpo. Kogan (1996) señala que el cuerpo es la frontera entre nuestro yo individual y nuestro yo social. Los cuerpos están sujetos a prácticas sociales que se fundan en la línea de la biología y la cultura. "Adornamos, maquillamos, vestimos y movemos nuestros cuerpos de formas que son impuestas por cada cultura (Kogan,1996: 5). La misma autora indica que algunos estudios de Birdwhistell señalan que se puede identificar el idioma que habla una persona por los gestos corporales, de tal manera que nuestros cuerpos no representan categorías naturales, sino construcciones sociales; también cita a Focault, quien sugiere que "el cuerpo es un nudo de relaciones de poder".

$E l$ poder. Éste, por un lado, se define como la habilidad de las personas para provocar la obediencia de los otros, a quienes se somete, es un ámbito en el que se producen conflictos y desacuerdos. Los que detentan el poder poseen algo que los otros valoran y necesitan o quieren, ya sea dinero o bienes materiales. Los detentadores del poder tienen los medios para sobornar o castigar. "Por definición, un sistema de estratificación de los sexos implica el poder superior de los hombres" (Saltzman, 1989: 41).

Autoridad. Es el poder legitimado, es la percepción tanto del que detenta el poder como de quien obedece. "La legitimidad del poder masculino está arraigada en la ideología sexual [asimismo] el poder y la autoridad existen en todos los niveles de análisis" (Saltzman,1989: 41).

Desigualdad. De acuerdo con Saltzman (1989), diversas teorías como las marxistas-feministas, teoría medio-estructural y microestructural, hacen hincapié en que la desigualdad entre los sexos se da y se mantiene principalmente porque los hombres cuentan con los medios para hacerlo. Existe una desigualdad estructurada, según la autora, la cual permite a los hombres sobornar o coaccionar a las mujeres para que éstas se comporten como ellos quieren. A pesar de ello, en la mayoría de las épocas y lugares se percibe esta coerción “y 
las mujeres no piensan conscientemente que estén más oprimidas que los hombres" (Saltzman, 1989: 30).

\section{Relaciones de género en los narcocorridos}

A través de la historia, el corrido (y otros géneros) ha sido una clara manifestación de las prácticas machistas y sexistas, las cuales aún prevalecen. Todavía encontramos discursos en los cuales se marca la separación de la mujer y del hombre. El ambiente del que nos hablan los narcocorridos es en gran parte un mundo de hombres. La habilidad en los negocios, la maña, la fuerza, la valentía, en suma todas las características positivas o negativas, se identifican con la hombría y el poder. De acuerdo con Valenzuela (2002), el corrido presenta puntos de vista masculinizados y una condición de subordinación hacia la mujer, y agrega que ésta participa:

como caja de resonancia [...] para hacer más evidentes las virtudes de los hombres [asimismo] las relaciones de género presentan con gran crudeza esta desigualdad emanada de la construcción sociocultural de hombres y mujeres... [pero también] presentan nuevos campos de actuación femenina (Valenzuela, 2002: 209).

Pero existen también algunas historias donde se habla del nuevo desempeño de la mujer dentro del mundo del tráfico de estupefacientes; el arrojo, la fuerza y el poder son comparables a los de los hombres; su conducta puede ser tan sensible y amorosa, agresiva, confiada y creyente como la más fiel devota. Son formas de valoración que los compositores dan a la mujer y la definen como la hembra valiente, quien no se anda con cuentos y muere como los hombres, "adquiere nuevos espacios de protagonismo en el narcocorrido [...] las mujeres despliegan facultades ponderadas en las culturas patriarcales, por ejemplo la valentía, la osadía o la frialdad para matar" (Valenzuela, 2002: 214).

\section{El narcotráfico en Sinaloa}

El origen del narcotráfico en Sinaloa no tiene fechas precisàs. En Lazcano Ochoa (1992) aparece la entrada de los chinos a Sinaloa a principios del siglo $\mathrm{XX}$, quienes introducen el cultivo de la amapola y el opio para su consumo y comercio, lo cual se puede considerar como el antecedente del tráfico ilegal de drogas. Sería la Segunda Guerra mundial la etapa que marcaría en defini- 
tiva el inicio de la producción a mayor escala, primero bajo convenio de los gobiernos estadounidense y mexicano, quienes accedieron a la siembra de amapola en el municipio de Badiraguato, enclavado en la sierra, para abastecer de morfina y heroína a Estados Unidos. Astorga, citado por González (1996), expone que el cultivo generó grandes beneficios económicos para los pobladores, sin embargo, al terminar el conflicto los dos gobiernos decidieron poner fin al convenio, lo que provocó que en adelante se convirtiera en siembra ilegal. El estado se transformó rápidamente, terminó la tranquilidad y dio paso a la violencia en sus diversas expresiones; el narcotráfico creó las condiciones para que ésta se generalizara.

A pesar de las campañas contra el tráfico de drogas llevadas a cabo por los distintos gobiernos en el estado; el problema derivó en otro fenómeno, el cual, por las proporciones y su extensa área de influencia ha crecido en forma inimaginable: la narcocultura, como lo expresa González (1996: 64):

La percepción de la gente se dividía; se tornaba, por lo menos, confusa: las leyes representaban (en cierto sentido siguen representando) el código ético del gobierno y la sociedad convencional; los corridos que celebraban y siguen celebrando) a los narcos y sus enfrentamientos con las fuerzas policíacas y el ejército constituían [...] el código de otra parte del conglomerado que lo transmitía (y siguen transmitiendo) con una eficacia despreciable. El estigma condenatorio se volvía emblema de prestigio y reconocimiento.

Esto nos da idea de cómo y hasta dónde el fenómeno está presente en el imaginario colectivo; por un lado reconoce el interés por combatir el problema, pero por otro enaltece los valores del narcotraficante, lo consagra como héroe y lo transmite en la música.

\section{Del corrido al narcocorrido}

Para hablar del narcocorrido es importante señalar que como nuevo género musical tiene su antecedente en el corrido tradicional, cuyos orígenes datan de la Independencia y eran la vía de expresión de los hechos y las causas por las cuales luchaban los caudillos y las consideraban justas. Vicente T. Mendoza (1954: VIII), un clásico en estos estudios, dice:

Transmitido por boca del vulgo [el corrido] ha alcanzado una dispersión que abarca no solamente el territorio nacional, sino rebasando las fronteras ha llegado a diversos puntos de la Unión Americana [...] para las multitudes iletradas de entonces constituía la única fuente de información de los sucesos más sobresalientes. 
En cuanto a su estructura literaria, el mismo autor la define como:

Género épico-lírico-narrativo [...] forma literaria en la que se apoya una frase musical [...] relata aquellos sucesos que hieren poderosamente la sensibilidad de las multitudes. Este género, por lo épico, es una derivación del romance castellano, del cual conserva su carácter narrativo de hazañas y combates; por lo lírico, deriva de la copla y del cantar, cuando relata hechos sentimentales; y de la jácara, toma el énfasis exagerado del machismo, las balandronadas, jactancias, engreimiento y soflama, propios de la germanía y en labios de jaques y valentones (1954: IX).

Sobre los narcocorridos, diversos datos registran antecedentes temáticos que dieron origen a composiciones sobre contrabando; según Hernández (2000), desde el siglo antepasado hubo personajes a quienes ya se les cantaba por dedicarse a transportar contrabando de textiles en la frontera norte de Tamaulipas y sur de Texas. Posteriormente, con las leyes de prohibición de Estados Unidos “convirtieron al alcohol en tema de corridos como 'Los tequileros' y (probablemente) 'El contrabando del paso' (Hernández, 2001: 331)". Este mismo autor anota, del decenio de 1940, a "La carga blanca" como el posible primer corrido cuyo tema sobre la cocaína es narrado abiertamente, y agrega que en la década de 1950 se canta "La Canela". A partir del decenio de 1970 hay una explosión musical sobre esta temática. De la Torre (2002: VII-VIII) aporta lo siguiente:

La aparición de los narcocorridos sinaloenses data de los años setenta, éstos son el registro histórico de la vida del narcotraficante, la expresión narcocultural de la violencia. Es un fenómeno musical que ha traspasado las fronteras de México, con una industria multimillonaria cuya popularidad va en aumento debido a que grandes grupos sociales de diversos países (Colombia, Estados Unidos, etc.) cantan con admiración las dudosas hazañas de los antihéroes, que son narcotraficantes de poca monta, hasta capos de renombre.

Los personajes del narcocorrido heredan el papel del héroe del corrido tradicional, son carismáticos, dispuestos a enfrentar situaciones de peligro, a arriesgar su vida, ponen a prueba la lealtad y el valor, generalmente al margen de la ley. De los más populares fueron el corrido de "Pedro Valdez", "Clave siete", "La banda del carro rojo", "Pacas de a kilo", "El número uno", "Los dos plebes", "Chito Cano", "Jefe de jefes", entre muchos más. También se popularizó "Lamberto Quintero", el cual narra uno de los enfrentamientos más sangrientos entre traficantes ocurridos en pleno centro de la ciudad de Culiacán y aún sigue en la memoria de muchas personas; pero quizás ninguno ha tenido la trascendencia y ha permanecido en "el gusto y la preferencia" del mexicano en general como "Contrabando y traición", mejor conocido como "Camelia la Texana", donde la participación de la mujer aparece activamente 
por primera vez; a partir de éste se escribirían otros temas sobre mujeres narcotraficantes como "Margarita la de Tijuana", "También las mujeres pueden”, "La Güera Yolanda", "La Jefa", "Las dos monjitas", "La fama de la pareja", "Cuatro narcas", entre otros.

Lamentablemente, el estado de Sinaloa es considerado como uno de los mayores productores de droga en el país; de ahí que sea, también, donde este tipo de música tenga arraigo entre la población. La fuerte existencia del narcotráfico y sus consecuencias traducidas en violencia, incremento en el consumo y adicción, así como en la influencia social y cultural, son el insumo para que gente del pueblo, de la ciudad y de todas las latitudes expresen, a través de la música, sus sentimientos, emociones y hasta juicios acerca de los hombres y mujeres implicados en este fenómeno. Las temáticas tradicionales de los corridos (historias sentimentales, sucesos históricos, hombres valientes o bandoleros comunes, lugares, etc.) se han transformado ante el cambio de las acciones; ahora el narcocorrido narra historias, las cuales en su mayoría destacan la violencia, la burla, la muerte, los tipos de droga, etcétera.

Pero también en otros estados productores de droga se tiene ésta práctica, ya que una gran parte de los narcocorridos localizados para esta investigación se refieren a mujeres de lugares, no sólo del país, sino del extranjero, como Tijuana, Monterrey, California, Las Vegas, San Antonio, Michoacán, Jalisco, Chihuahua, Durango, Tamaulipas, entre otros.

De la presencia de la mujer en estos temas musicales podemos decir que su participación es equiparable a la de los hombres, la descripción y la referencia hacia ella no es diferente a la de ellos, encontramos mujeres asesinas, traidoras, traficantes de drogas, negociadoras, religiosas, leales; es otra dimensión hasta ahora poco estudiada, quizás por no estar acorde con las expectativas morales que la sociedad tiene de la mujer. A nuestro juicio, sea cual sea el papel de la mujer, su principal problema será el de ser estudiada desde una dimensión integral, no importa su oficio, legal o ilegal. El fenómeno existe, forma parte de un colectivo cultural y no puede eludirse. No por representar un oficio denigrante y generador de conductas negativas ha de ocultársele. La sola existencia de los estudios de género y el ser parte de una construcción social le permiten ser sujeto de estudio.

\section{Simbología en los personajes femeninos}

A manera de breves antecedentes, encontramos que en la época de la Revolución mexicana, cuando el corrido tomó su carácter definitivo, se asigna a la mujer un rol de madre, pareja-esposa y revolucionaria; pero su conducta es transformada al romper con los patrones establecidos en ese momento, cuan- 
do toma las armas, defiende su territorio y se gana un lugar en la acción, por ejemplo "La Adelita", "La Valentina", "La Rielera", "Marieta", de los más populares. Posteriores a esta etapa están: "Rosita Alvírez”, “Teresa Durán”, "Micaila" y otros.

En la actualidad, como indica Valenzuela (2002), "la mujer adquiere nuevos espacios de protagonismo en el narcocorrido", su inclusión en él ya no es sólo para "cosificarla" o para exhibirla como trofeo, sino que alude a la mujer valiente, leal, traidora, cruel, violenta. La estrecha relación entre el ambiente real del narcotráfico y las historias narradas en la música son elementos fundamentales para su interpretación.

La primera parte de este análisis inicia con una clasificación por temas y/o asuntos de acuerdo a los contenidos. Por razones de espacio y con el propósito de ofrecer una representación significativa de los roles y símbolos encontrados, los corridos no se presentan en su totalidad, sólo una parte y, a su vez, estrofas de los mismos (ver cuadro página siguiente)

\section{Simbología}

A partir de la clasificación, en los siguientes análisis, tomaremos algunas estrofas de los corridos correspondientes al o los asuntos encontrados en las historias, procurando la identificación de símbolos y la interpretación más aproximada de las unidades referenciales (personajes, lugares, hechos).

Traición y muerte

Las relaciones de amor son a veces el espacio de conflicto; se puede amar o se puede odiar hasta el sacrificio. La solidaridad, cuando no es correspondida, suele desencadenar reacciones violentas en el ambiente del narco. Así, encontramos en "Contrabando y traición", corrido famoso interpretado por Los Tigres del Norte, lo siguiente: "Una hembra si quiere a un hombre por él puede dar la vida, pero hay que tener cuidado, si esa hembra se siente herida, la traición y el contrabando son cosas incompartidas".

Emilio dice a Camelia

hoy te das por despedida con la parte que te toca

tú puedes rehacer tu vida

yo me voy pa' San Francisco

con la dueña de mi vida. 


\section{Clasificación de los corridos de traficantes} de drogas por temas $y / o$ asuntos

\begin{tabular}{|c|c|}
\hline Tema y/o asunto & Título del narcocorrido \\
\hline Traición y muerte & $\begin{array}{l}\text { "Contrabando y traición" } \\
\text { "Margarita la de Tijuana" } \\
\text { "Juana la contrabandista" }\end{array}$ \\
\hline Venganza y muerte & $\begin{array}{l}\text { "La Camelia" } \\
\text { "Juana la contrabandista" }\end{array}$ \\
\hline Engaho, astucia, droga y muerte & $\begin{array}{l}\text { "Las dos monjitas" } \\
\text { "La rubia y la morena" }\end{array}$ \\
\hline Droga y muerte & $\begin{array}{l}\text { "Pollitas de cuenta" } \\
\text { "La pecosa" } \\
\text { "El retén de Las Norias" } \\
\text { "La camioneta gris" }\end{array}$ \\
\hline Belleza, poder, redes y muerte & $\begin{array}{l}\text { "También las mujeres pueden" } \\
\text { "Cuatro narcas" } \\
\text { "La Reina del Sur" (versión 2) } \\
\text { "El retén de Las Norias" } \\
\text { "Socias de la mafia" } \\
\end{array}$ \\
\hline Consumo suntuario, belleza, poder, autonomia & $\begin{array}{l}\text { "La Reina del Sur" (versión 2) } \\
\text { "Las panteras" } \\
\text { "Ya encontraron a Camelia" } \\
\text { "La Jefa" } \\
\text { "Cuatro narcas" } \\
\text { "También las mujeres pueden" }\end{array}$ \\
\hline Belleza, sociedad (amistad), redes, poder y control & $\begin{array}{l}\text { "Socias de la mafia" } \\
\text { "La Jefa" } \\
\text { "El retén de Las Norias" } \\
\text { "La Reina del Sur" (versión 1) } \\
\text { "Los líos de Zenaida" } \\
\text { "Cuatro narcas" } \\
\end{array}$ \\
\hline Lealtad, sexo y muerte & "La fama de la pareja" \\
\hline Belleza, sexo, corrupción y violencia & $\begin{array}{l}\text { "La Guera Yolanda" } \\
\text { "La dama de la Suburban" } \\
\text { "Socias de la mafia" } \\
\text { "La Jefa" }\end{array}$ \\
\hline Belleza, autonomía, poder y control & $\begin{array}{l}\text { "La dama de la Suburban" } \\
\text { "La Jefa" } \\
\text { "La Güera Yolanda" } \\
\text { "La Reina del Sur" (versiones 1y 2) }\end{array}$ \\
\hline Fortaleza, elogio y belleza & - La Reina del Sur" (versión 1) \\
\hline
\end{tabular}

$\mathrm{El}$ éxito en el negocio está asegurado, "sin preocuparse por la condición moral incorporada" (Valenzuela, 2002: 140). El sexismo y la discriminación sexual aparecen como elementos de conflicto por parte de Emilio al utilizar a Camelia como un objeto de uso a su voluntad; Olivier (en Porzecanski, 1996) señala que el discurso del hombre resulta mortífero para la mujer, ya que al tomarla como objeto le arrebata su lugar como sujeto y decide en lugar de ella lo que debe resultarle bueno. De ese modo, es el hombre quien define el lugar y el lenguaje femenino. 
Si ya la traición es el peor crimen en la sociedad de los traficantes, en el amor desencadena la ira de la mujer, con consecuencias fatales. Una mujer enojada es una fuerza incontrolable; para Camelia, ser traicionada en el amor es más importante que la traición en el negocio; a esta infidelidad responde con la muerte de su amado infiel.

En "Juana la contrabandista", de autor e intérpretes no identificados, encontramos una doble venganza y relaciones de rivalidad a partir de relaciones amorosas no fructificadas: primero, la traición del hombre hacia la mujer termina con la muerte de éste. El honor y la dignidad son más fuertes que la entrega apasionada, aunque a la mujer le cueste la cárcel. Sin embargo, escapa de ella para seguir en el negocio. En segundo término, la muerte de la protagonista a manos del hijo de su rival en amores.

Se escapó de la prisión
Juana la contrabandista
porque mató a su querido
la tuvieron prisionera
le quería poner el cuerno
con Catita la chivera...
Juana la contrabandista
se prendó de un forastero
pero no se imaginaba
que era un hombre gatillero
era hijo de la chivera
y la echó en un voladero.

Engaño, astucia, droga y muerte

Por ser un género musical que relata específicamente sucesos sobre estupefacientes, la muerte es una consecuencia casi natural y recurrente en los narcocorridos. Matar es un asunto por demás "normal" entre narcotraficantes, grupos de poder o autoridades, con ello se apareja el engaño y la astucia..., y la crueldad.

"La rubia y la morena", de Fredy Bojorquez:

Eran la rubia y la negra hembras de mucho valor...

$A$ un hombre sacrificaron

le cortaron la cabeza

cuando llegaron a la aduana

mostraron mucha tristeza

que hasta los guardias lloraron

dándoles sus condolencias... 
Adentro de la cabeza

kilo y medio acomodaron

del valioso polvo blanco

para llevarlo a Chicago

y así quitarse de pobres

cruzando varios estados...

En la ribera del Bravo

hay un hombre sin cabeza

y los guardias de la aduana

llorando tras de las rejas

y la morena y la rubia

en busca de otras cabezas.

En estas estrofas los roles protagónicos contienen elementos negativos, rasgos socialmente rechazados y atribuidos comúnmente a los hombres, cuando en realidad la mujer también los manifiesta en los narcocorridos.

Otra historia similar la representan "Las dos monjitas", interpretada por el Grupo Exterminador, donde la los asuntos adquieren connotaciones burlescas:

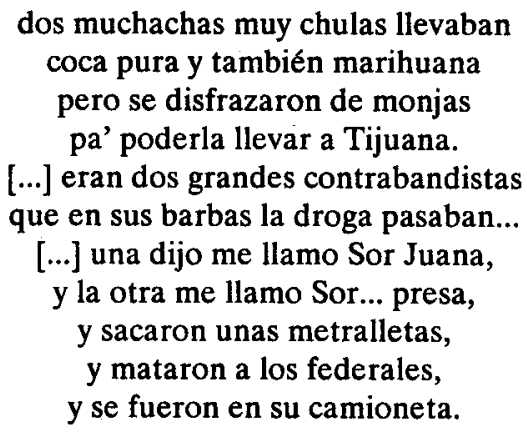

En el mundo del narco es imprescindible el uso de armas, sobre todo de mucha potencia, sinónimo de violencia y poder. En estas historias se registran los enfrentamientos donde participan mujeres que asesinan y recurren a todo tipo de argucias por defender su negocio, la carga o el dinero, burlar la autoridad, etcétera; son compromisos implícitos dentro de los códigos del narcoambiente.

Belleza, poder, redes y muerte

Los y las narcotraficantes no realizan su negocio solos, generalmente están asociados o agrupados en los llamados cárteles de la droga. Sus operaciones 
abarcan enormes áreas. Las luchas por el control y el poder sobre otros grupos es parte inherente de su condición. Las actividades relacionadas con otros grupos nacionales e internacionales las encontramos en los siguientes corridos:

"Socias de la mafia", de Los Tigres del Norte:

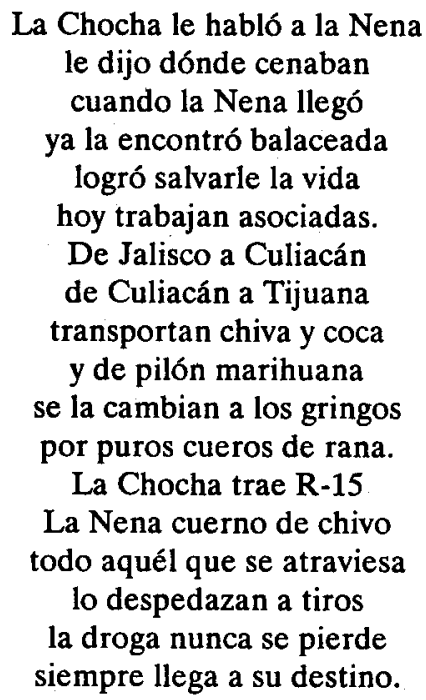

La mujer valiente se sale de los esquemas en el mundo del tráfico de drogas, responde con su fuerza e inteligencia a la hora de enfrentar situaciones difíciles. Demuestra que los hombres no son los únicos valientes.

La imagen de una mujer bonita en la música despierta diversas emociones y la representan con una gran belleza física. Pero también se resalta el valor y el arrojo. En el "también... pueden" indican igualdad" entre los géneros, de fuerza y poder, reconociendo que las mujeres son tan peligrosas como ellos.

"También las mujeres pueden", de Los Tigres del Norte:

También las mujeres pueden

y además no se andan con cosas

cuando se enojan son fieras

esas caritas hermosas

y con pistola en la mano

se vuelven repeligrosas...

Tres muchachas esperaban

procedentes de Colombia

ahí quedaron de verse

con las dos de Sinaloa.

Todas vestían de vaquero 


$$
\begin{aligned}
& \text { y chamarra de vaqueta } \\
& \text { también cargaban pistola } \\
& \text { debajo de la chaqueta } \\
& \text { mucho dinero en la bolsa } \\
& \text { y muy buenas camionetas. }
\end{aligned}
$$

Además de poder y control, destacan elementos simbólicos de la imagen física, por ejemplo el consumo suntuario: "vestían de vaquero, chamarra de vaqueta y mucho dinero"; así como instrumentos de trabajo: "cargaban pistola, muy buenas camionetas"; "indispensables" para el "negocio". Pearson (1993) nos habla de la existencia de una comunicación artifactual, con la cual intercambiamos mensajes a través de los objetos que son parte de la imagen como la ropa, los accesorios, el maquillaje, entre otros: también determina nuestra edad, nuestro rol y estatus, actitudes y estilo de vida. Por otra parte, la ropa permite identificarnos con una cultura o subcultura a la que pertenecemos; por tal razón, no es extraño que estas heroínas hayan sido identificadas por su vestimenta y se advierta fácilmente la actividad desempeñada.

$$
\begin{gathered}
\text { De pronto se oyen disparos } \\
\text { unas mujeres caían } \\
\text { las tres eran colombianas } \\
\text { lo dijo la policía } \\
\text { y las dos de Sinaloa } \\
\text { a Tierra Blanca volvían. }
\end{gathered}
$$

El poder y la violencia nuevamente se aprecian; un negocio mal llevado se paga con la muerte.

$$
\begin{aligned}
& \text { También las mujeres pueden } \\
& \text { aunque me duela aceptarlo } \\
& \text { lo digo aquí y donde quiera } \\
& \text { porque pude comprobarlo } \\
& \text { que como un hombre se mueren } \\
& \text { eso no hay que dudarlo. }
\end{aligned}
$$

Reconoce el valor de las mujeres, aunque como hombre le duele aceptarlo. A este respecto, en el apartado elaborado por Pearson sobre los roles femeninos, destaca que para el hombre feminista es menos importante el género biológico en una persona que otro tipo de factores, por lo que reconoce todas las capacidades de la mujer.

"Cuatro narcas", de Los Pumas del Norte 


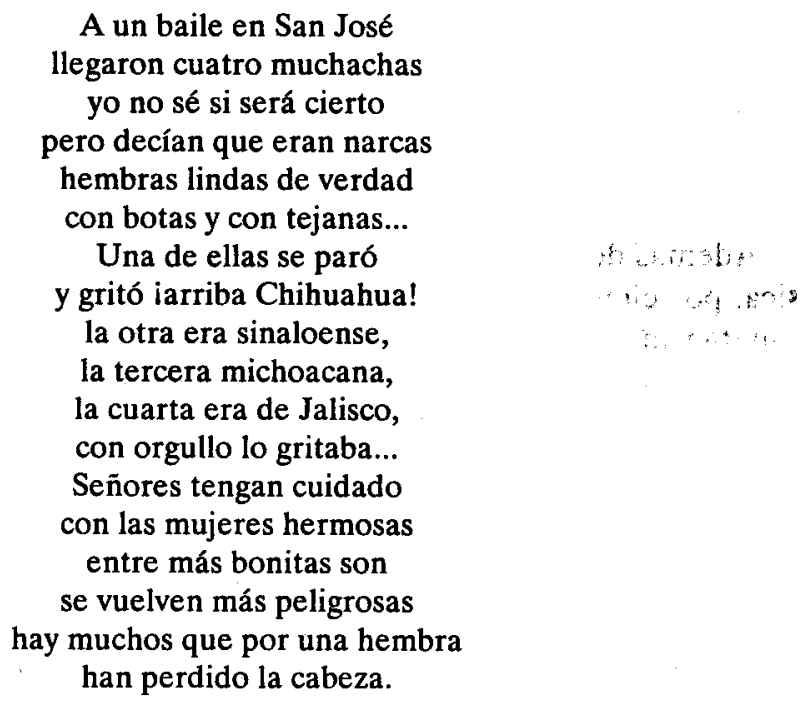

Los lugares no sólo indican las redes, en los narcocorridos se definen desde diversas características, como lo señala Valenzuela (2002: 243):

reconocimiento exaltando el lugar de origen [...] sitio definido por los ámbitos íntimos [...] ponderación de las características de su gente, la cual se define por atributos positivos como son el respeto, la valentía y la belleza [...] o región mercado definida desde las redes de operación del narcotráfico.

Lealtad, sexo y muerte

Como ya se ha planteado, los códigos de honor son muy importantes para el narcotraficante, ya sean por amistad, sociedad o por relaciones amorosas. El preservar estos códigos les fortalece.

"La fama de la pareja", de Los Tigres del Norte
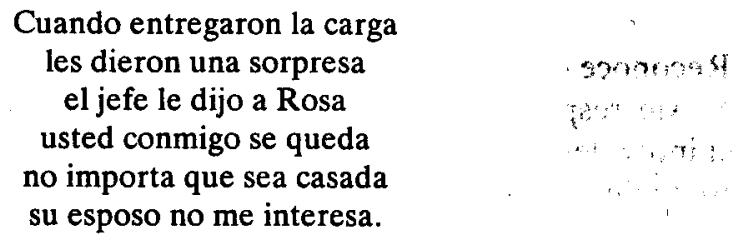

El sexismo es una forma de discriminación que le da el derecho, tanto al hombre como a la mujer, de poseer y ejercer dominio sobre los demás. Esta discriminación se acentúa en esta estrofa, cuando Rosita, después de realizar 
"el negocio", es objeto de acoso sexual por parte del jefe, quien le manifiesta la intención de obtener sus favores sexuales; el poder del hombre sobre la mujer es claro en el imperativo: "usted conmigo se queda", casos frecuentes entre narcotraficantes, quienes toman a las mujeres que les gustan y las retienen hasta que se cansan de ellas. Esta situación también plantea una desigualdad del hombre hacia la mujer, al no darle el trato de iguales como "empresarios".del mismo negocio, "al fin y al cabo es simplemente una mujer".

$$
\begin{aligned}
& \text { Ya cuando estaban solitos } \\
& \text { Rosita de una maleta } \\
& \text { sacó una cuarenta y cinco } \\
& \text { y le apuntó a la cabeza } \\
& \text { yo sólo soy de mi esposo } \\
& \text { se lo he jurado en la iglesia. }
\end{aligned}
$$

El honor y los valores religiosos están por encima de todo. En muchos sentidos las relaciones íntimas se caracterizan por un elevado nivel de solidaridad y proximidad, como lo señala Wheeless (citado por Pearson); y según Brown y Gilman (citados por Tannen), la solidaridad significa igualdad, en contraste con el poder.

Otra historia sobre el asunto del poder y la muerte es la que nos narran en "La Jefa", una forma distinta de describir a la heroína:

"La Jefa", del Grupo Exterminador

Siguen buscando a la Jefa
que mueve todo el negocio
el gobierno mexicano
tiene fama de muy bravo
pero a la Jefa del contrabando
le hacen los puros mandados...
Su madre es mexicana,
de ahí sacó lo valiente,
es una hembra muy brava
que ha matado a mucha gente,
tres policías, seis soldados
y de pilón un teniente.

Parte del poder de los y las narcotraficantes tiene que ver con el reconocimiento y la protección que reciben de sus iguales y de las propias autoridades. De la misma forma en que su ascendencia mexicana le pondera características muy específicas: ser muy valiente, brava y asesina, no le teme a nada 
ni a nadie. El haber matado a miembros de la autoridad la coloca en un nivel importante, por eso es la Jefa.

A la ciudad de Chicago
la Jefa ya ha controlado
en California es socia
de esos dos de Durango
y en la ciudad de Tijuana
su contacto es michoacano.
Ese estado de Texas
por mexicanos controlado
de Chihuahua y Tamaulipas
son los vatos más pesados
pero dicen que es la Jefa
la que les surte el mercado.
Los contactos de la Jefa
están allá en Monterrey
en Chihuahua y en San Luis
Michoacán y Nayarit
y un sinaloense por novio
es el que la hace feliz.

La insistencia por señalar los lugares y el acaparamiento, en estas estrofas es un claro ejemplo de la dimensión y la capacidad de los grupos controladores de la droga, en este caso al mando de una mujer. También encontramos en ella una relación amorosa, su capacidad de amar y ser feliz.

Belleza, sexo, corrupción y violencia

Uno de los elementos sobresalientes de la mujer en los narcocorridos es su habilidad para sobornar por medio de su belleza utilizando su cuerpo.

"La Güera Yolanda", de la banda La Mentira

\author{
Tenía los ojos bonitos \\ como flor de jacaranda \\ el cuerpo muy bien formado \\ y se llamaba Yolanda \\ pero también la mataron \\ era el jefe de la banda.
}

El cuerpo como construcción social y atributo femenino es el recurso para la descripción de la belleza femenina. Santamaría (1997) señala que las formas curvas tienen más que ver con la belleza que las formas esquinadas (cuadradas) es decir, porque éstas se desenvuelven en torno a un centro 
(estructura corporal), con lo cual presentan una imagen concreta de la cerrazón en sí, que es la expresión simbólica de la belleza femenina (Simmel, citado por Santamaría, 1997: 93). Acompañando a un cuerpo bien formado está una cara bonita, la metáfora como recurso literario tiene su función complementando la descripción de Yolanda: "tenía los ojos bonitos como flor de jacaranda".

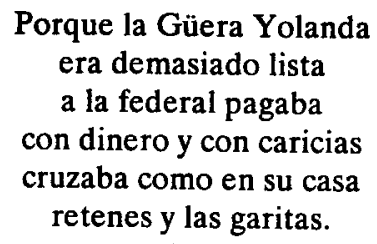

La inteligencia de la Güera Yolanda se traduce en la utilización de su cuerpo; es su atractivo y forma de seducir; es el sexo por conveniencia como medio de corrupción.

Yolanda se devolvió
apretando una granada
y le quitó la espoleta
cuando la ley se acercaba
tres agentes federales
esa muerte no esperaban.
Le empezaron a tirar
y aquella mujer bonita
de entre sus senos sacó
una escuadra chiquitita
y antes de morir mató
a dos que tenía cerquita.

Ante la situación de violencia obliga la reacción. "La droga amplifica los límites y mina las opciones de vida... "al final hay que morir en la raya"” (Valenzuela, 2002: 126).

Fortaleza y elogio

Dentro de las valoraciones positivas otorgadas a la mujer, destacan su fortaleza para soportar el sufrimiento y el dolor que a veces le provocan situaciones negativas. En la primera versión de "La Reina del Sur", aunque no indica ciertamente la actividad, la podemos deducir por la novela del mismo nombre, la cual dio origen al primer corrido; en la historia encontramos una espiritualidad y un reconocimiento a los sentimientos y las emociones de una mujer en el destierro involuntario. 
“La Reina del Sur” (versión 1), autor: César Güemes Cerril

$$
\begin{gathered}
\text { Eres mujer y fantasma } \\
\text { eres leyenda y legión } \\
\text { cien por ciento mexicana } \\
\text { española de adopción... } \\
\text {... Corazón de quince tiros } \\
\text { blindado contra el dolor, } \\
\text { que no se metan contigo, } \\
\text { bugambilia en esplendor... } \\
\text { ¿Cuándo vienes, Teresita, } \\
\text { a tu tierra y su cuidado? } \\
\text { ¿Cuándo vuelves, fiera niña? } \\
\text { Sinaloa te está esperando... }
\end{gathered}
$$

En la siguiente versión la actividad es clara; el elogio, al calor de la emoción de tener una mujer muy valiente, se asume en el hombre feminista, quien no duda de la fuerza y la valentía de la mujer.

"La Reina del Sur" (versión 2), autor: Teodoro Bello, Los Tigres del Norte

Voy a cantar un corrido

escuchen muy bien mis compas

para la reina del sur

traficante muy famosa

nacida allá en Sinaloa

la tía Teresa Mendoza...

Supo aprender el acento

que se usa por toda España

demostró su jerarquía

como la más noble dama

a muchos los sorprendió

Teresa la mexicana...

Era la reina del sur

allá en su tierra natal

Teresa la mexicana

del otro lado del mar

una mujer muy valiente

que no la van a olvidar.

En ambos casos aparecen los lugares de referencia, "la región nostálgica donde se produce un proceso de traslación cultural de la nación para resignificarla en el nuevo contexto y en cualquier parte del extranjero donde vive 'nuestra gente"' (Valenzuela, 2002: 243). 


\section{Consideraciones finales}

Los corridos son una forma de conocer parte de la historia del mundo del narcotráfico y todas sus posibles articulaciones y aristas, desde las cuales se pueden construir los símbolos y los significados, en especial los referidos al rol femenino. En ellos, la participación de la mujer en el narcomundo la ha llevado a ocupar el lugar de heroína, hembra valerosa, mujer bella e inteligente; valoraciones desde un machismo arraigado que se mimetiza en la mujer, como si el valor fuera atributo exclusivamente masculino.

Con la enorme presencia del narcotráfico y su influencia en todos los niveles de la sociedad, las consecuencias se manifiestan con violencia, consumo y muerte, las cuales, al trascender la esfera de lo social-cultural, propician una nueva cultura y desempeño de un nuevo rol femenino, representado simbólicamente en los narcocorridos. Las distintas valoraciones otorgadas en esta música la hacen ser percibida por el imaginario colectivo de manera muy diferente.

Droga, muerte, corrupción, belleza, sexo, sexismo, poder, dinero, son signos y significaciones que definen la vida y el ambiente del narcomundo. Sin ser ésta una postura de apoyo a favor de este nuevo rol, apreciamos una mujer en busca de un espacio en un mundo dominado por los hombres, y al encontrarlo lo defiende. Es la búsqueda de la equidad en oposición a la desigualdad y la discriminación sexual. Dentro de las historias narradas en los narcocorridos, muchas de éstas tienen contenidos fantasiosos, pero con mucha aproximación a una realidad inocultable —como diría José Manuel Valenzuela-y en donde los medios de comunicación llevan su parte; por un lado, al difundir esta música, y por el otro, al darnos cotidianamente información sobre este fenómeno.

Sin ser este trabajo un estudio comparativo entre hombres y mujeres, encontramos más similitudes que diferencias, por ejemplo: 4 I comportamiento, el lenguaje utilizado, el vestuario, uso de armas y vehículos, el control y el poder, las acciones y transacciones, entre otras. Capacidad e inteligencia no le faltan a la mujer para desempeñar su trabajo en el narcomundo.

Esto es lo que nos muestran los narisocorridos. No tenemos intención de asumir posturas a favor o en contra, sor simplemente simbologías encontradas dentro de un discurso, las cuales pueden diferir de otras opiniones. Como ya se dijo en párrafos anteriores, el fen jmeno existe, no puede eludirse, sin embargo, se puede contrarrestar con $\mathrm{m}$;jores programas educacionales, con responsabilidades compartidas. Lo que sí debemos considerar es que el narcotráfico no se combate combatiendo al narcocorrido. 


\section{Bibliografía}

De la Torre Barrón, Arcelia (2002), “Del corrido al narcocorrido. Una ventana a la historia contemporánea de Sinaloa", en Revista Mexicana de Comunicación, núm. 76, vII-VIII, julio-agosto.

González, Ronaldo (1996), Merodeos (una mirada generacional), México, Dirección de Investigación y Fomento de Cultura Regional (Difocur-Sinaloa).

Hernández, Guillermo (2000), "El corrido, ayer y hoy. Notas para su estudio", en Valenzuela Arce, José Manuel (coord.), Entre la magia y la historia, tradiciones, mitos y leyendas de la frontera, $2^{\mathrm{a}}$ ed., Tijuana, BC, El Colegio de la Frontera Norte-Plaza y Valdés.

Krippendorff, Klauss (1993), Metodología de análisis de contenido. Teoria y práctica, España, Paidós.

Lazcano y Ochoa, Manuel (1992), Una vida en la vida sinaloense. Una visión autorizada de la historia de la entidad y del fenómeno social del narcotráfico, Culiacán, Sinaloa, México.

Mendoza, Vicente T. (1954), 9ª reimp. (2001), El corrido mexicano, Fondo de Cultura Popular.

Pearson, Judy C. et al. (1993), Comunicación y género, España, Paidós.

Porzencanski, Teresa (1996), "El silencio, la palabra y la construcción de lo femenino", en Diá-logos de la Comunicación, Lima, Perú, Federación Latinoamericana de Facultades de Comunicación Social, núm. 46, octubre. Propp, Vladimir (1986), Morfología del cuento ruso, 2a ed., México, Colofón. Ramos Escandón, Carmen (comp.) (1991), El género en perspectiva: de la dominación universal a la representación múltiple, Universidad Autónoma Metropolitana.

Rodríguez Pérez, Beatriz y Corrales Burgueño, Antonio (comps.) (1999), Género y ciencias sociales, UAS-Cobaes-Suntuas, sección Académicos.

Tannen, Déborah (1996), Género y discurso, Barcelona, España, Paidós. Valenzuela Arce, José Manuel (2002), Jefe de jefes. Corridos y narcocultura en México, México, Plaza y Janés. 